\title{
The association of non-Hodgkin's lymphoma with glomerulonephritis
}

\author{
J.A. Girón González, M. Yebra Bango, F. Merino Morales, J.L. Menéndez Caro, \\ F.J. Diego Marín and A. Durántez Martínez
}

Department of Internal Medicine I, Clinica Puerta de Hierro, 28035 Madrid, Spain.

\begin{abstract}
Summary: Paraneoplastic glomerulonephritis is an infrequent complication in the course of nonHodgkin's lymphoma (21 cases to date). We report a modality not previously described: mesangioproliferative glomerulonephritis and mixed lymphocytic lymphoma, and review the literature on the subject. The onset of the two processes was simultaneous. Antitumour treatment induced simultaneous remission of the lymphoma and glomerulonephritis.
\end{abstract}

\section{Introduction}

The nephrotic syndrome is a paraneoplastic manifestation in $10 \%$ of all adult cases in some series (Lee $e t$ al., 1966; Eagen \& Lewis, 1977). Hodgkin's disease has been the most commonly associated tumour, but cases have also been described in connection with other haematological diseases and carcinomas (Fer et al., 1981; Richmond et al., 1962).

There are only a few publications which associate glomerulonephritis (GN) with non-Hodgkin's lymphomas (NHL). We report a case of NHL presenting with nephrotic syndrome and renal failure due to mesangioproliferative GN.

\section{Case report}

A 67 year old white woman was admitted to our hospital because of generalized oedema for 8 months.

On physical examination, the only positive findings were inguinal lymphadenopathy and anasarca. Laboratory data showed a normal haemogram; erythrocyte sedimentation rate, $110 \mathrm{~mm}$ in the first hour; urine protein excretion, $6.60 \mathrm{~g} / 24 \mathrm{~h}$; hyaline-cellular and granular casts; 9 to 10 erythrocytes and 15 to 20 leucocytes per high power field; serum total proteins, $41 \mathrm{~g} / \mathrm{l}$; albumin, $21 \mathrm{~g} / \mathrm{l}$; creatinine clearance, $15 \mathrm{ml} /$ minute. The following results were either normal or negative: urine culture, immunoelectrophoresis, antistreptolysin titre, hepatitis B virus serology, VDRL, antinuclear antibodies, complement, cryoglobulin and circulating immune complexes.

Lymph gland biopsy showed mixed diffuse lym-

Correspondence: J.A. Girón, M.D.

Accepted: 19 June 1986

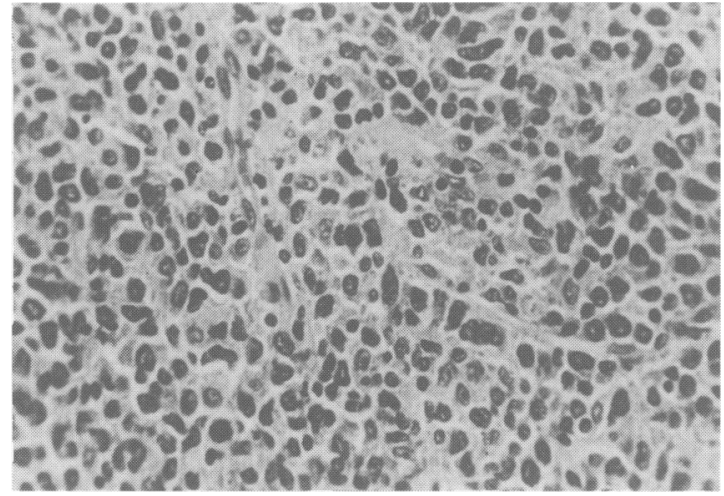

Figure 1 Lymph gland biopsy showing abnormal architecture with diffuse cellularity and loss. Evident destruction of the ganglion with diffuse cellularity and loss of the marginal sinus (light microscopy). (H \& $\mathrm{E} \times 400$ )

phocytic lymphoma (Figure 1). Chest X-ray, pedal lymphogram and hepatic and bone marrow biopsies were normal.

Kidney biopsy was performed from which eight glomeruli were obtained, some of them augmented in size and with an elevated number of nuclei. Deposits of fuchsinophilic material were detected in the basement membrane and the mesangium. No signs of amyloidosis, vasculitis or infiltration by lymphoma were observed (Figure 2). Granular deposits of IgM and $\mathrm{C}_{3}$ were detected by immunological techniques in mesangium and capillaries.

The patient was treated with CVP (cyclophosphamide, vincristine and prednisone) and diuretics. The treatment was continued for a total of 12 months.

(C) The Fellowship of Postgraduate Medicine, 1986 

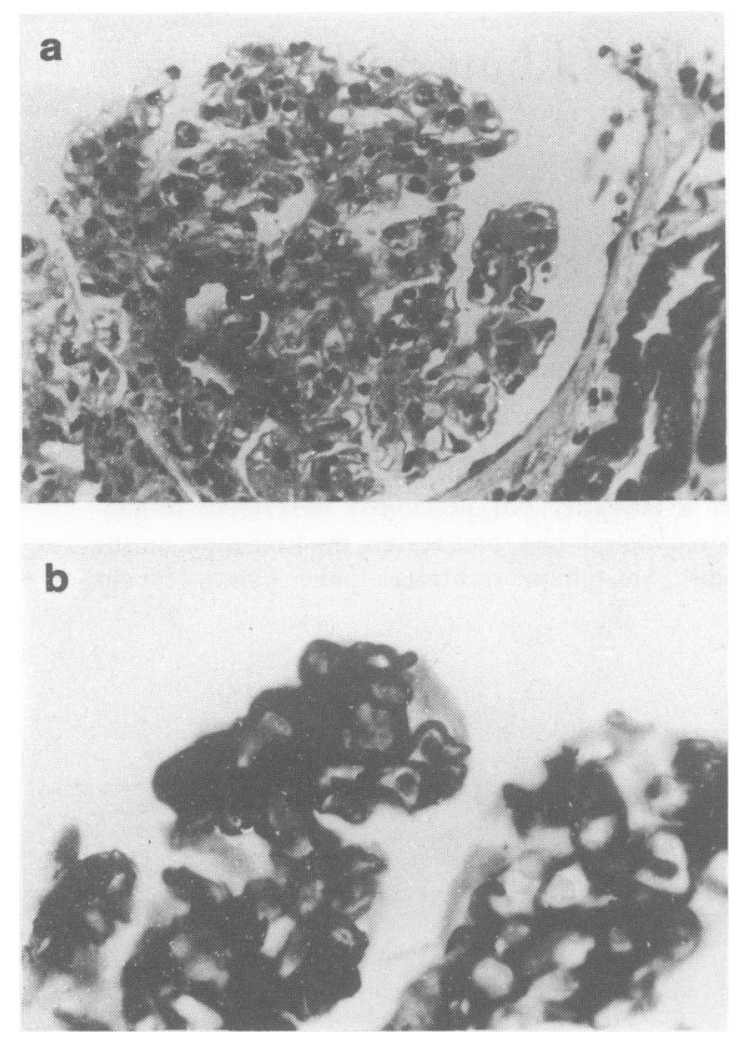

Figure 2 Glomerulus with augmented mesangial matrix, occupying the entire capsular area. (a) Haematoxylineosin $\times 400$ and (b) haematoxylin-eosin and silver stain $\times 800$.

There was complete remission of tumour and nephropathy which continued 7 years after presentation.

\section{Discussion}

We have found 22 cases of NHL and different types of GN, including our own. We have excluded the six cases described by Gupta (1973) and one of those described by Muggia \& Ultmann (1971) given the absence of precise histological data. The remaining 15 cases are shown in Table I.

The average age of the patients was 47 years, range 7-74 years and the male: female ratio was 10:4. The patient's sex is not mentioned in one case (Gluck et al, 1973).

The presentation of GN and NHL was simultaneous in seven cases. Four cases presented with clinical manifestations of nephropathy (nephrotic syndrome in two and nephrotic syndrome plus kidney failure in the other two). Lymphadenopathy was the first mani- festation in the three cases. There is no information regarding the presentation sequence in the remaining case.

The pathology of NHL is difficult to compare due to the diversity of the nomenclature employed in the classification. The majority ( 9 cases) were in stage IV, $\bar{O}$ according to the Ann Arbor staging system (Carbone 흐 et al., 1971), at the time of diagnosis.

A wide range of histological glomerular lesions was $\overparen{ه}$ detected as shown in Table I. In cases 12 and 13, besides GN, renal infiltration by lymphoma was observed. It is not possible to establish a relationship $\stackrel{\circ}{\circ}$ between the histological types of NHL and GN.

In ten cases the evolution of both processes is $\stackrel{\omega}{\sigma}$ mentioned explicitly. Eight of them (cases 2, 7, 8, 9, 10, 11,12 and 15) presented parallel courses in that the 3 . progression or remission of the tumour was accompanied by a similar course in the kidney disease. The clinical course was independent in cases 6 and 13. In ${ }_{\perp}$ the case described by Hyman et al. (1973) (case 6), GN appeared 4 months after the appearance of the lym- $\vec{A}$ phoma, which was at that time in complete remission. 0 Banks et al. (1984) (case 13) describe the onset of focal proliferative $\mathrm{GN}$ in a patient who had been diagnosed $\square$

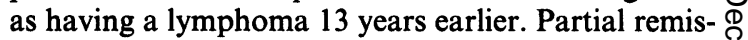
sion of the nephropathy was achieved and maintained $\frac{\mathbb{}}{3}$ by means of a specific treatment, despite the progres- $\square$ sion of the lymphoma.

Minimal change glomerulonephritis has been t $\vec{\oplus}$ most common histological type of nephropatkọ associated with Hodgkin's disease (Eagen \& Lewis; 1977). However, proliferative (Lowry et al., 1971), 主 membranous (Row et al., 1975) and focal segmental sclerosis (Powderly et al., 1985) glomerular lesions have been described. There is, however, no predomin- $\mathbb{D}$ ant histological type associated with non-Hodgkin's $\stackrel{2}{\Rightarrow}$ lymphoma.

Glomerulonephritis can appear before, simultaneously or after the appearance of the lymphoma, whether it be Hodgkin's or non-Hodgkin's. When glomerular disease occurs at the same time as lymphoma, treatment of the neoplasia may suppress associated nephropathy. Although the antineoplastic 3 . drugs might act directly on the glomerulus, the $\delta$ regression after radiation therapy to extrarenal areas suggests that a direct effect of therapy on the 0 glomerulus is not always the cause of the therapeutic response of the nephropathy.

The pathogenesis of GN in this type of patient is not clear. Alteration of T lymphocytes in patients with $\sigma$ neoplasms (Shalhoub, 1974; Moorthy et al., 1976) has N been mentioned as the disorder responsible for min- N imal-change nephropathy. In other histological types, $\sigma$ the occasional finding of tumoral antigens and antibodies and of antigen-antibody complexes in serum and renal eluate (Costanza et al., 1973; Mendes $\stackrel{\infty}{\rightarrow}$ Da Costa et al., 1974; Couser et al., 1974; Sutherland et 7 


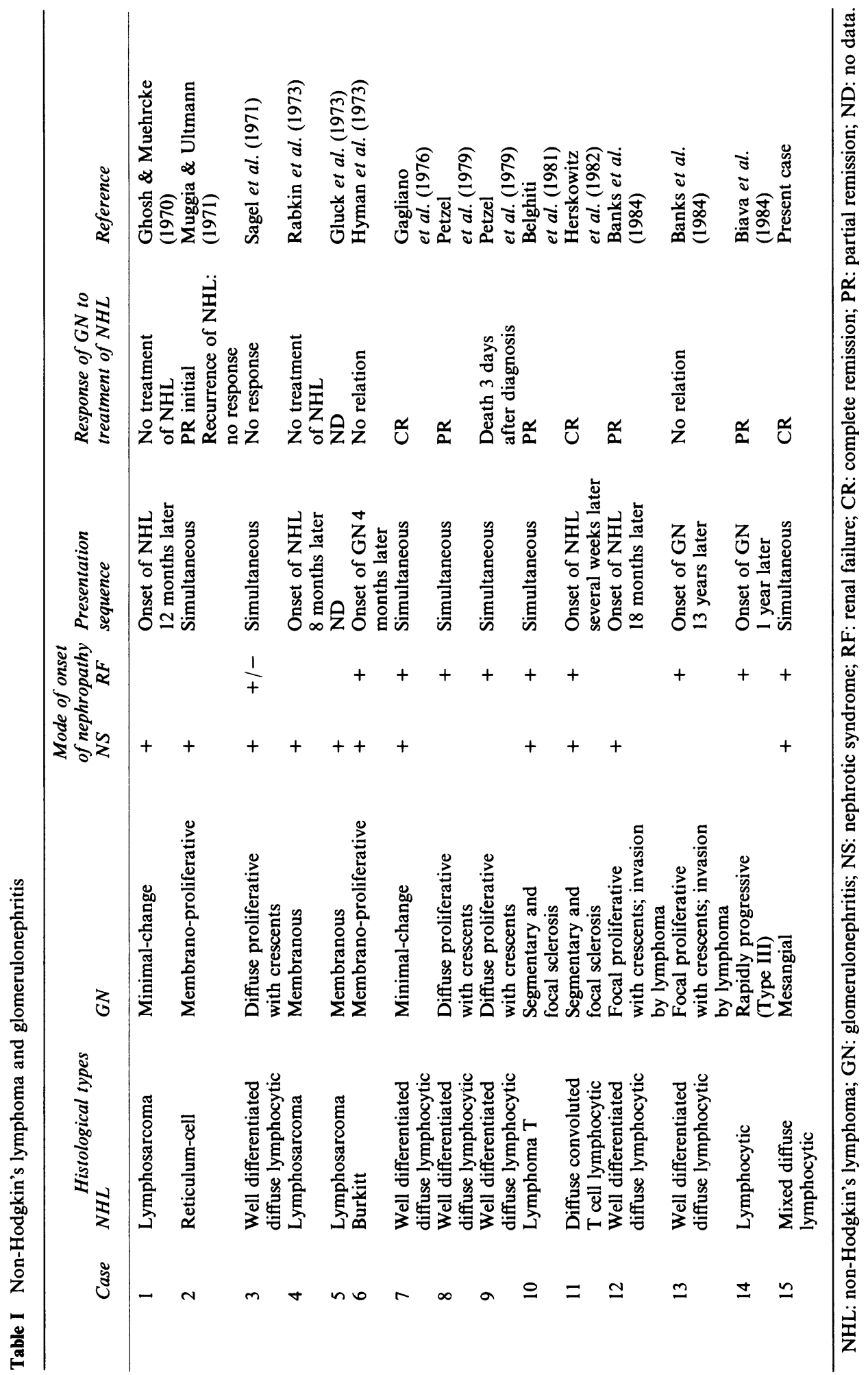


al., 1974; Pascal et al., 1976), suggests an immune complex-mediated mechanism. Helin et al. (1980), in a study of 24 patients with different types of neoplasms without clinically manifested kidney disorder, demonstrated the existence of glomerular electron-dense complexes in 11 of them and a significant correlation with the presence of circulating antibodies. From the group of patients dealt with in our review, only one had circulating immune complexes and cryoglobulins were detected in two. Finally, it is possible that the association between neoplasms and GN is a coincidence, with independent evolution presented in some

\section{References}

BANKS, R.A., KINGSWOOD, J.C., SLADE, R., TRIBE, C.R., HARISON, P.R. \& MACKENZIE, J.C. (1984). Glomerulonephritis, non-Hodgkin's lymphoma and leucocytoclastic vasculitis. American Journal of Nephrology, 4, 114.

BELGHITI, D., VERNANT, J.P., HIRBEC, G., GUBLER, M.C., ANDRE, C. \& SOBEL, A. (1981). Nephrotic syndrome associated with T-cell lymphoma. Cancer, 47, 1878.

BIAVA, C.G., GONWA, T.A., NAUGHTON, J.L. \& HOPPER, J. JR. (1984). Crescentic glomerulonephritis associated with nonrenal malignancies. American Journal of Nephrology, 4, 208.

CARBONE, P.P., KAPLAN, H.S., MUSSHOFF, K., SMITHERS, D.W. \& TUBIANA, M. (1971). Report of the committee on Hodgkin's staging classification. Cancer Research, 31, 1860.

COSTANZA, M.E., PINN, V., SCHWARTZ, R.S. \& NATHANSON, L. (1973). Carcinoembryonic antigen-antibody complexes in a patient with colonic carcinoma and nephrotic syndrome. New England Journal of Medicine, 289, 520.

COUSER, W.G., WAGONFELD, J.B., SPARGO, B.H. \& LEWIS, E.J. (1974). Glomerular deposition of tumor antigen in membranous nephropathy associated with colonic carcinoma. American Journal of Medicine, 57, 962.

EAGEN, J.W. \& LEWIS, E.J. (1977). Glomerulopathies of neoplasia. Kidney International, 11, 297.

FER, M.F., MCKINNEY, T.D., RICHARDSON, R.L., HANDE, K.R., OLDHAM, R.K. \& GRECO, F.A. (1981). Cancer and the kidney: renal complications of neoplasms. American Journal of Medicine, 71, 704.

GAGLIANO, R.G., COSTANZI, J.J., BEATHARD, G.A., SARLES, H.E. \& BELL, J.D. (1976). The nephrotic syndrome associated with neoplasia: an unusual paraneoplastic syndrome. American Journal of Medicine, 60, 1026.

GHOSH, L. \& MUEHRCKE, R.C. (1970). The nephrotic syndrome: a prodrome to lymphoma. Annals of Internal Medicine, 72, 379.

GLUCK, M.C., GALLO, G., LOWENSTEIN, J. \& BALDWIN, D.S. (1973). Membranous glomerulonephritis: evolution of clinical and pathologic features. Annals of Internal Medicine, 78, 1.

GUPTA, R.K. (1973). Immunohistochemical study of glomerular lesions in retroperitoneal lymphomas. American Journal of Pathology, 71, 427.

HELIN, H., PASTERNACK, A., HAKALA, T., PENTINEN, K. \& WAGER, O. (1980). Glomerular electron-dense deposits cases (Hyman et al., 1973: Banks et al., 1984). However, the discovery of a greater incidence of neoplasms in some types of GN (Lee et al., 1966; 은 Gluck et al., 1973; Biava et al., 1984; Row et al., 1975) would lend support to a causal relationship.

In conclusion, we have presented a case of non- $\bar{C}$ Hodgkin's lymphoma associated with nephrotic syn- $\frac{D}{2}$ drome and kidney failure which widens the spectrum $\frac{\overline{\bar{N}}}{\overline{\mathrm{D}}}$ of glomerulonephritis in connection with this type of $\Phi$ lymphoma, extending it to include mesangioproliferative glomerulonephritis, an association which had not been described previously.

and circulating immune complexes in patients with malig- is nant tumours. Clinical Nephrology, 14, 23.

HERSKOWITZ, L.J., GOTTLIEB, R.P. \& TRAVIS, S. (1982). Nephrotic syndrome associated with non-Hodgkin's lym- phoma. Clinical Pediatrics, 21, 441.

HYMAN, L.R., BURKHOLDER, P.M., JOO, P.A. \& SEGAR, W.E. (1973). Malignant lymphoma and nephrotic syndrome. Journal of Pediatrics, 82, 207.

LEE, J.C., YAMAUCHI, H. \& HOPPER, J. JR. (1966). The association of cancer and the nephrotic syndrome. Annals of Internal Medicine, 64, 41.

LOWRY, W.S., MUNZENRIDER, J.E. \& LYNCH, G.A. (1971) Nephrotic syndrome in Hodgkin's disease. Lancet, i, 12థ

MENDEZ DA COSTA, C.R., DUPONT, E., HAMERS, R HOOGUE, R., DUPRIES, F. \& POTRLIEPE, R. (1974 Nephrotic syndrome in bronchogenic carcinoma: report two cases with immunochemical studies. Clinical Nephrology, 2, 245.

MOORTHY, A.V., ZIMMERMAN, S.W. \& BURKHOLDER, P.M. (1976). Nephrotic syndrome in Hodgkin's disease. Evidence for pathogenesis alternative to immune complex disease. American Journal of Medicine, 61, 471.

MUGGIA, F.M. \& ULTMANN, J.E. (1971). Glomerulonephritis or nephrotic syndrome in malignant lymphoma, reticulum-cell type. Lancet, i, 805.

PASCAL, R.R., IANNACCONE, P.M., ROLLWAGEN, F.M., HARDING, T.A. \& BENNET,S.J. (1976). Electron microscopy and immunofluorescence glomerular immune complex deposits in cancer patients. Cancer Research, 36, 43.

PETZEL, R.A., BROWN, D.C., STALEY, N.A., McMILLEN, J.A., SIBLEY, R.K. \& KJELLSTRAND, C.M. (1979). Crescentic glomerulonephritis and renal failure associated with malignant lymphoma. American Journal of Clinical Path- $\mathrm{O}$ ology, 71, 728.

POWDERLY, W.G., CANTWELL, B.M.G., FENNELLY, J.J., $\frac{1}{0}$ WARDE, P., MCCABE, M.M. \& TOWERS, R.P. (1985). Renal glomerulopathies associated with Hodgkin's disease. Can- N cer, 56, 874.

RABKIN, R., THATCHER, G.N., DIAMOND, L.H. \& EALES, L. 용 (1973). The nephrotic syndrome, malignancy and immun- $\mathrm{\omega}$ osuppression. South African Medical Journal, April 14, ర్ 605.

RICHMOND, J., SHERMAN, R.S., DIAMOND, H.D. \& $\frac{0}{\Phi}$

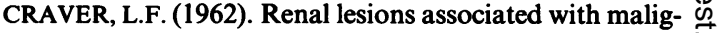
nant lymphomas. American Journal of Medicine, 32, 184. 
ROW, P.G., CAMERON, J.S., TURNER, D.R., EVANS, D.J., WHITE, R.H.R., OGG, C.S., CHANTLER, C. \& BROWN, C.B. (1975). Membranous nephropathy. Long-term follow-up and association with neoplasia. Quarterly Journal of Medicine, 44, 207.

SAGEL, J., MULLER, H. \& LOGAN, E. (1971). Lymphoma and the nephrotic syndrome. South African Medical Journal, 45, 79.
SHALHOUB, R.J. (1974). Pathogenesis of lipoid nephrosis: a disorder of T-cell function. Lancet, ii, 556.

SUTHERLAND, J.C., MARKHAM, R.V. \& MARDINEY, M.R. (1974). Subclinical immune complexes in the glomeruli of kidneys postmortem. American Journal of Medicine, 57, 536. 